\title{
Os gêneros Staurastrum, Staurodesmus e Xanthidium (Desmidiaceae, Zygnemaphyceae) da Lagoa do Caçó, Estado do Maranhão, Nordeste do Brasil
}

\author{
Maria José Dellamano-Oliveira ${ }^{1,3}$, Célia Leite Sant ${ }^{\prime}$ Anna $^{2}$, Gloria Massae Taniguchi $^{1}$ e \\ Pedro Américo Cabral Senna ${ }^{1(\dagger)}$
}

Recebido: 28.06.2007; aceito: 19.06.2008

\begin{abstract}
The genera Staurastrum, Staurodesmus and Xanthidium (Desmidiaceae, Zygnemaphyceae) from Caçó Pond, Maranhão State, Norhteastern Brazil). This work is a contribution to the knowledge of Desmidiaceae biodiversity of Brazilian Northeastern region, poorly known in relation to its phycological flora. Collections were performed at eight sampling stations, following a transect on the longest lake axis during the rainy (April 1999) and dry (November 1999) seasons. The samples were concentrated in a $20 \mu \mathrm{m}$ mesh net and preserved on $4 \%$ formalin solution. Analysis revealed that Desmidiaceae was the dominant group qualitatively. A total of 29 taxa were identified among the three genera, 18 belonging to Staurastrum, eight to Staurodesmus and three to Xanthidium. Excepting Staurastrum rotula, S. teliferum var. grönbladii and Staurodesmus validus var. subvalidus, all species found represents new records to Maranhão State.
\end{abstract}

Key words: Biodiversity, Desmidiaceae, Zygnemaphyceae

RESUMO - (Os gêneros Staurastrum, Staurodesmus e Xanthidium (Desmidiaceae, Zygnemaphyceae) da Lagoa do Caçó, Estado do Maranhão, Nordeste do Brasil). Este trabalho é uma contribuição ao conhecimento da biodiversidade das desmidiáceas da região Nordeste do Brasil, cujas informações são ainda escassas. As coletas foram realizadas em oito estações de amostragem, seguindo um transecto no eixo mais longo da lagoa, nos períodos de chuva (abril de 1999) e seca (novembro de 1999). As amostras foram coletadas com uma rede de plâncton de $20 u$ m de malha e preservadas em formalina 4\%. A análise do material revelou que Desmidiaceae foi o grupo dominante qualitativamente. Um total de 29 táxons foram identificados entre os três gêneros, sendo 18 de Staurastrum, oito de Staurodesmus e três de Xanthidium. Com exceção de Staurastrum rotula, S. teliferum var. grönbladii e Staurodesmus validus var. subvalidus, todos os outros táxons constituemse em citações pioneiras para o estado do Maranhão.

Palavras-chave: Biodiversidade, Desmidiaceae, Zygnemaphyceae

\section{Introdução}

As desmídias constituem um grupo de algas muito importante quando considerada a riqueza e diversidade de espécies em inúmeros ambientes e habitats, bem como pela variedade de formas geométricas e padrões de decoração de parede (Brook 1981). Embora bastante estudadas em algumas regiões brasileiras, como por exemplo, nos Estados de São Paulo e Rio de Janeiro (Bicudo \& Bicudo 1965, Bicudo \& Azevedo 1977, Bicudo \& Sormus 1982, Bicudo \& Samanez 1984, Sophia 1987, 1991 e 1999, Sormus 1991, Bicudo \& Castro 1994, Sormus \& Bicudo 1994, Marinho \& Sophia 1997, Bicudo et al. 1998, Silva 1999, Gil \&
Bicudo 2000, Bicudo \& Gil 2003, Matsuzaki et al. 2004, Faustino \& Bicudo 2004, Ferragut et al. 2005), entre outros, particularmente para a região Nordeste as publicações são poucas e muitas vezes limitam-se a listas de espécies.

O estado do Maranhão é considerado uma região de transição entre a Amazônia e o Nordeste brasileiro. Os ambientes estudados nesta área apresentam características semelhantes aos descritos para região Amazônica e a flora encontrada no Estado assemelhase àquelas documentadas para regiões da Amazônia (Förster 1969, 1974, Huszar 1994, Huszar \& Sophia 1996, Uherkóvich 1976, 1981, 1984). Para o Nordeste, esta semelhança também existe e é confirmada em

1. Universidade Federal de São Carlos, Departamento de Ecologia e Biologia Evolutiva, Rodovia Washington Luiz, km 235, Caixa Postal 676, 13565-905 São Carlos, SP, Brasil

2. Instituto de Botânica, Caixa Postal 3005,01061-970 São Paulo, SP, Brasil

3. Autor para correspondência: pdeol@ig.com.br 
publicações como Förster (1964), Martins \& Bicudo (1987) e Bicudo \& Martins (1988), entre outros.

Em geral, o conhecimento sobre a ficoflora no Estado do Maranhão está contido em aproximadamente 16 trabalhos: cinco referem-se a estuários (dados não publicados), três em baías (Oliveira et al. 1986, EskinaziLeça et al. 1985, Lavôr-Fernandes 1988), um em lagoa urbana eutrófica (Lavôr-Fernandes 1987), um em rio (Araújo et al. 1998), um em lagos de dunas (dados não publicados), um no sistema lacustre do Parque Nacional dos Lençóis Maranhenses (Araújo 2000), dois de lagos da baixada maranhense (Barbieri et al. 1989, Almeida et al. 2005), um em reservatório (Pompêo et al. 1998) e um em lagos marginais do rio Turiaçu (Nogueira et al. 2005). Especificamente sobre as desmidiáceas, não existem trabalhos publicados até o momento.

Portanto, o presente trabalho visa contribuir com o conhecimento da flora de desmídias dos gêneros Staurastrum Meyen ex Ralfs, Staurodesmus Teiling e Xanthidium Ehrenberg emend. Ralfs na lagoa do Caçó, contribuindo assim com os estudos de biodiversidade ficológica do Estado do Maranhão.

\section{Material e métodos}

A Lagoa do Caçó $\left(2^{\circ} 58^{\prime} \mathrm{S}\right.$ e $\left.43^{\circ} 25^{\prime} \mathrm{W}\right)$ localizase ao Norte do estado do Maranhão (Município de Primeira Cruz), a $100 \mathrm{~km}$ do mar. O clima da região é tropical semi-úmido com precipitação entre 1.500 e 1.750 mm/ano (Nimer 1989) controlado, essencialmente, pelos deslocamentos sazonais da zona de convergência intertropical (ZCIT) e pela atividade dos ventos alísios. Na região da lagoa, os ventos alísios proporcionam a ocorrência de seis meses de chuva, quando a ZCIT encontra-se ao Sul do Equador (janeiro a junho) e seis meses de seca, quando a ZCIT localizase ao Norte do Equador (julho a dezembro). A tabela 1 mostra algumas das características morfométricas da Lagoa do Caçó, bem como valores médios $(\mathrm{n}=38)$ das variáveis limnológicas abióticas.

Tabela 1. Características morfométricas e valores médios $(n=38)$ das variáveis limnológicas abióticas da lagoa do Caçó em 1999. (Fonte: Dellamano-Oliveira et al. 2003).

\begin{tabular}{lcc}
\hline Características & Valores Médios & Valores Médios \\
\cline { 2 - 3 } & Abril & Novembro \\
\hline Comprimento máximo & $5 \mathrm{Km}$ & $5 \mathrm{Km}$ \\
Largura máxima & $500 \mathrm{~m}$ & $500 \mathrm{~m}$ \\
Profundidade máxima & $10 \mathrm{~m}$ & $8 \mathrm{~m}$ \\
Temperatura & $29,1{ }^{\circ} \mathrm{C}$ & $28,8^{\circ} \mathrm{C}$ \\
Transparência & $4,6 \mathrm{~m}$ & $4,3 \mathrm{~m}$ \\
Zona eufótica & total & total \\
Condutividade & $35,4 \mu \mathrm{cm}^{-1}$ & $35,1 \mu \mathrm{Sm}^{-1}$ \\
pH & 5,0 & 5,3 \\
O. D. & $6,6 \mathrm{mg} \mathrm{L}^{-1}$ & $6,7 \mathrm{mg} \mathrm{L}^{-1}$ \\
PT & $8,16 \mu \mathrm{g} \mathrm{L}^{-1}$ & $6,65 \mu \mathrm{g} \mathrm{L}^{-1}$ \\
NT & $246,78 \mu \mathrm{g} \mathrm{L}^{-1}$ & $288 \mu \mathrm{g} \mathrm{L}^{-1}$ \\
Razão NT/PT & 33,4 & 45,16 \\
\hline
\end{tabular}

As amostras foram coletadas nos meses de abril (período chuvoso) e novembro (período seco) em oito estações, seguindo um transecto no eixo mais longo da lagoa. Foram utilizadas redes de plâncton de 20 $\mu \mathrm{m}$ de abertura de malha e garrafa tipo Van Dorn. As amostras coletadas com rede foram fixadas em formalina $4 \%$ para posterior identificação dos táxons e as com garrafa foram congeladas e utilizadas para determinação das concentrações dos nutrientes totais e dissolvidos. As estações 1 e 8 situam-se na região litorânea da lagoa onde há macrófitas aquáticas e as estações 2 a 7 são limnéticas, sendo que em duas (4 e 6) há a presença de macrófitas.

O exame do material foi realizado com o auxílio de microscópio binocular marca Carl Zeiss, modelo Axioscop, com ocular micrometrada, equipado com 
contraste de fase, optovar e câmara-clara. As amostras mais representativas em relação às desmídias foram depositadas no Herbário Científico do Estado "Maria Eneyda P. Kauffmann Fidalgo" (SP), do Instituto de Botânica da Secretaria do Meio Ambiente do Estado de São Paulo, sob os números SP336201, SP336288SP336300, SP336319-SP336320.

O sistema de classificação utilizado foi o de Round (1971). Para a descrição dos táxons encontrados, as seguintes abreviaturas referentes aos limites métricos foram utilizadas: $\mathrm{C}=$ comprimento celular; $\mathrm{L}=$ largura celular; $\mathrm{Cp}=$ comprimento dos processos, $\mathrm{Ccp}=$ comprimento com processos; $\mathrm{Csp}=$ comprimento sem processos; Lcp = largura com processos; Lsp = largura sem processos; $\mathrm{Cce}=$ comprimento com espinhos; Cse $=$ comprimento sem espinhos; Lce $=$ largura com espinhos; Lse = largura sem espinhos; $\mathrm{I}=$ istmo; $\mathrm{CF}$ $=$ contraste de fase.

\section{Resultados e Discussão}

Foram identificados 29 táxons distribuídos entre os três gêneros: Staurastrum (18), Staurodesmus (oito) e Xanthidium (três). A riqueza de táxons dos gêneros estudados no período chuvoso foi de 26 e no período seco foi de 12 táxons. Alguns táxons como Staurastrum disputatum var. sinense, S. teliferum var. pecten e Staurodesmus mamillatus foram encontrados somente no período seco. Por outro lado, o seguinte grupo de táxons ocorreu somente no período chuvoso: Staurastrum dilatatum var. dilatatum $\mathrm{f}$. dilatatum, $S$. cf. grallatorium, $S$. muticum var. muticum f. minus, $S$. novae-caesarae var. brasiliense, S. rotula, S. teliferum var. groenbladii, S. tentaculiferum, S. tetracerum var. tetracerum $\mathrm{f}$. tetracerum, $S$. vestitum var. subanatinum, Staurodesmus connatus var. connatus, S. dejectus var. borealis f. amazonensis, S. indentatus, S. megacanthus var. minus, S. tortus, S. validus var. validus, S. validus var. subvalidus, Xanthidium cf. eckertii (tabela 2).

Com relação à distribuição dos táxons na lagoa (zonas litorânea e limnética), a tabela 2 mostra que, no período chuvoso, a maioria dos táxons ocorre na zona litorânea e limnética. No período de seca todos os táxons, exceto Staurastrum columbetoides var. ginzbergeri, foram encontrados apenas na zona limnética.

\section{Chave para identificação dos gêneros estudados}

1. Células com ângulos lisos ou ornamentados com processos Staurastrum

1. Células com ângulos ornamentados com espinhos

2. Espinhos angulares dispostos em um único plano Staurodesmus

2. Espinhos angulares dispostos em dois planos Xanthidium

Staurastrum Meyen ex Ralfs

Chave para identificação dos táxons de Staurastrum encontrados na lagoa do Caçó

1. Ângulos das semicélulas prolongados em processos

2. Ângulos das semicélulas prolongados em 2 processos

3. Células aproximadamente tão longas quanto largas S. tetracerum f. tetracerum

3. Células mais longas que largas

4. Constrição mediana profunda (istmo ca. 4,3 $\mu \mathrm{m}$ larg.)

4. Constrição mediana rasa (istmo $3,8-6,1 \mu \mathrm{m}$ larg.)

5. Semicélulas trapeziformes

6. Processos angulares convergentes S. cf. grallatorium

6. Processos angulares horizontais S. columbetoides var. ginsbergeri

5. Semicélulas de outras formas

7. Semicélulas subcampanuladas S. leptocladum var. cornutum

7. Semicélulas sub-retangulares S. triundulatum var. floridense

2. Ângulos das semicélulas prolongados em 3 ou mais processos

8. Ângulos das semicélulas prolongados em 3 processos 
9. Face das semicélulas com espinhos S. tentaculiferum

9. Face das semicélulas crenulada ou com grânulos

10. Margem apical das semicélulas crenulada S. tetracerum f. trigona

10. Margem apical das semicélulas com grânulos S. vestitum var. subanatinum

8. Ângulos das semicélulas prolongados em 4 ou mais processos

11. Face das semicélulas lisa S. rotula

11. Face das semicélulas com espinhos ou grânulos

12. Face das semicélulas com espinhos S. steliferum

12. Face das semicélulas com grânulos

13. Constrição mediana moderada, istmo em forma de U..... S. novae-caesarae var. brasiliense

13. Constrição mediana rasa, istmo em forma de $\mathrm{V}$ S. margaritaceum

1. Ângulos das semicélulas arredondados ou truncados, não prolongados em processos

14. Parede celular lisa S. muticum f. minus

14. Parede celular com grânulos ou espinhos

15. Parede celular com grânulos

16. Vista apical 3-angular S. dilatatum

16. Vista apical 4-angular S. disputatum var. sinense

15. Parede celular com espinhos

17. Células sem os espinhos tão longas quanto largas S. teliferum cf. var. pecten

17. Células sem os espinhos ca. 1,7 vezes mais longas que largas S. teliferum var. grönbladii

Staurastrum columbetoides West \& West var. ginzbergeri (Grönb.) Scott, Acta Bot. Fennic. 69: 79. $1965 \equiv$ S. ginzbergeri Grönb., Acta Soc. Sci. Fennic. II B, 2(6): 25. 1945.

Figuras 1, 50

Células ca. 1,3 vez mais longas que largas sem os processos; constrição mediana profunda, istmo aberto; semicélulas trapeziformes, margem apical côncava, margens laterais côncavas na porção superior e convexas na porção inferior, margens basais côncavas, ângulos apicais prolongados em 2 longos processos 2-denteados, posicionados diagonalmente; face das semicélulas com 3 grânulos próximos ao istmo; vista apical não observada. $\mathrm{Cp}=40,2-59,7 \mu \mathrm{m}, \mathrm{Ccp}=76,5$ $102,3 \mu \mathrm{m} ; \mathrm{Csp}=17,1-19,9 \mu \mathrm{m} ; \mathrm{Lcp}=53,2-75,0 \mu \mathrm{m}$; $\mathrm{Lsp}=13,0-15,3 \mu \mathrm{m} ; \mathrm{I}=(3,0-) 4,3-7,6(-11,4) \mu \mathrm{m}$.

Material estudado: BRASIL. MARANHÃO: Barreirinhas, Lagoa do Caçó, 12-IV-1999, M.J.Dellamano-Oliveira s.n.(SP336288); idem, 13-IV-1999, M.J.DellamanoOliveira s.n. (SP336289); idem, 18-XI-1999, M.J. Dellamano-Oliveira s.n. (SP336290); idem, 14-IV1999, M.J. Dellamano-Oliveira s.n. (SP336291); idem, 15-IV-1999, M.J. Dellamano-Oliveira s.n. (SP336292); idem, 20-XI-1999, M.J. DellamanoOliveira s.n. (SP336293); idem,17-IV-1999, M.J. Dellamano-Oliveira s.n. (SP336296); idem, 22-XI-
1999, M.J. Dellamano-Oliveira s.n. (SP336297); idem, 19-IV-1999 M.J. Dellamano-Oliveira s.n. (SP336300); idem, 24-XI-1999, M.J. DellamanoOliveira s.n. (SP336301).

Primeiro registro de ocorrência no estado do Maranhão. Difere da variedade típica por possuir processos muito longos $(\mathrm{Cp}=40,2-59,7 \mu \mathrm{m})$.

Staurastrum dilatatum (Ehr.) Ralfs var. dilatatum $\mathrm{f}$. dilatatum, Brit. Desm.,p. 133. $1848 \equiv$ S. dilatatum Ehr., Infus: 143. 1838.

Figuras 2-3, 54-55

Células aproximadamente tão longas quanto largas; constrição mediana profunda, amplamente aberta; semicélulas subtriangulares, margem apical convexa, margens basais levemente côncavas divergindo para os ângulos laterais arredondados; parede celular granulosa, grânulos dispostos em séries concêntricas em torno dos ângulos; vista apical triangular, margens côncavas entre os lobos. $\mathrm{C}=13,8$ $27,5 \mu \mathrm{m} ; \mathrm{L}=13,0-29,8 \mu \mathrm{m} ; \mathrm{I}=9,0-9,2 \mu \mathrm{m}$.

Material estudado: BRASIL. MARANHÃO: Barreirinhas, Lagoa do Caçó, 12-IV-1999, M.J.Dellamano-Oliveira s.n. (SP336288); 17-IV-1999, M.J. DellamanoOliveira s.n. (SP336296). 
Tabela 2. Distribuição espacial e temporal dos táxons estudados.

\begin{tabular}{|c|c|c|c|c|}
\hline \multirow[t]{2}{*}{ Táxons } & \multicolumn{2}{|c|}{ Período chuvoso } & \multicolumn{2}{|c|}{ Período seco } \\
\hline & Zona limnética & Zona litorânea & Zona limnética & Zona litorânea \\
\hline Staurastrum columbetoides var. ginzbergeri & $\mathrm{X}$ & $\mathrm{X}$ & $\mathrm{X}$ & $\mathrm{X}$ \\
\hline S. dilatatum var. dilatatum f. dilatatum & $\mathrm{X}$ & $\mathrm{X}$ & & \\
\hline S. disputatum var. sinense & & & $\mathrm{X}$ & \\
\hline S.cf. grallatorium & $\mathrm{X}$ & & & \\
\hline S. grallatorium var. brasiliense & $\mathrm{X}$ & $\mathrm{X}$ & $\mathrm{X}$ & \\
\hline S. leptocladum. var. cornutum f. cornutum & $\mathrm{X}$ & $\mathrm{X}$ & $\mathrm{X}$ & \\
\hline S. margaritaceum var. margaritaceum & $\mathrm{X}$ & & $\mathrm{X}$ & \\
\hline S. muticum var. muticum f. minus & & $\mathrm{X}$ & & \\
\hline S. novae-caesarae var. brasiliense & & $\mathrm{x}$ & & \\
\hline S. rotula & $\mathrm{X}$ & $\mathrm{X}$ & & \\
\hline S. steliferum var. steliferum & $\mathrm{X}$ & $\mathrm{x}$ & $\mathrm{X}$ & \\
\hline S. teliferum var. groenbladii & $\mathrm{X}$ & $\mathrm{X}$ & & \\
\hline S. teliferum cf. var. pecten & & & $\mathrm{X}$ & \\
\hline S.tentaculiferum & $\mathrm{X}$ & $\mathrm{X}$ & & \\
\hline S. tetracerum var. tetracerum f. tetracerum & $\mathrm{X}$ & $\mathrm{X}$ & & \\
\hline S.tetracerum var. tetracerum f. trigona & $\mathrm{X}$ & & $\mathrm{X}$ & \\
\hline S. triundulatum var. floridense & $\mathrm{x}$ & $\mathrm{X}$ & $\mathrm{X}$ & \\
\hline S. vestitum var. subanatinum & $\mathrm{X}$ & $\mathrm{X}$ & & \\
\hline Staurodesmus connatus. var. connatus & $\mathrm{X}$ & $\mathrm{X}$ & & \\
\hline S. dejectus var. borealis f. amazonensis & $\mathrm{X}$ & $\mathrm{x}$ & & \\
\hline S.indentatus & $\mathrm{X}$ & & & \\
\hline S.mamillatus & & & $\mathrm{x}$ & \\
\hline S. megacanthus var. minus & $\mathrm{X}$ & & & \\
\hline S.tortus & $\mathrm{X}$ & $\mathrm{X}$ & & \\
\hline S. validus var. validus & $\mathrm{X}$ & & & \\
\hline S. validus var. subvalidus & & $\mathrm{X}$ & & \\
\hline Xanthidium. cf. eckertii & $\mathrm{X}$ & & & \\
\hline$X$. fragile & $\mathrm{X}$ & $\mathrm{x}$ & $\mathrm{X}$ & \\
\hline X. regulare & $\mathrm{X}$ & $\mathrm{X}$ & $\mathrm{X}$ & \\
\hline Total & 23 & 19 & 12 & 01 \\
\hline
\end{tabular}

Primeiro registro de ocorrência no estado do Maranhão.

\section{Staurastrum disputatum West \& West var. sinense}

(Lütkem.) West \& West, Monogr. 4: 176. $1912 \equiv$ S. sinense Lütkem., Ann. Nat. Hofmuseums 15: 124. 1900.

Figuras 4-5

Células ca.1,2 vez mais longas que largas; constrição mediana moderada, istmo alongado com margens subpareadas; semicélulas subcampanuladas, margem apical reta a levemente convexa, ângulos laterais arredondados, margens basais côncavas; parede celular lisa, exceto pela presença de 4 séries de grânulos na região apical dos lobos; vista apical 4 angular. $\mathrm{C}=$ ca. $27,1 \mu \mathrm{m} ; \mathrm{L}=$ ca. $21,4 \mu \mathrm{m} ; \mathrm{I}=$ ca. $8,5 \mu \mathrm{m}$.

Material estudado: BRASIL. MARANHÃO: Barreirinhas, Lagoa do Caçó, 22-XI-1999, M.J.Dellamano-Oliveira s.n. (SP336297). 

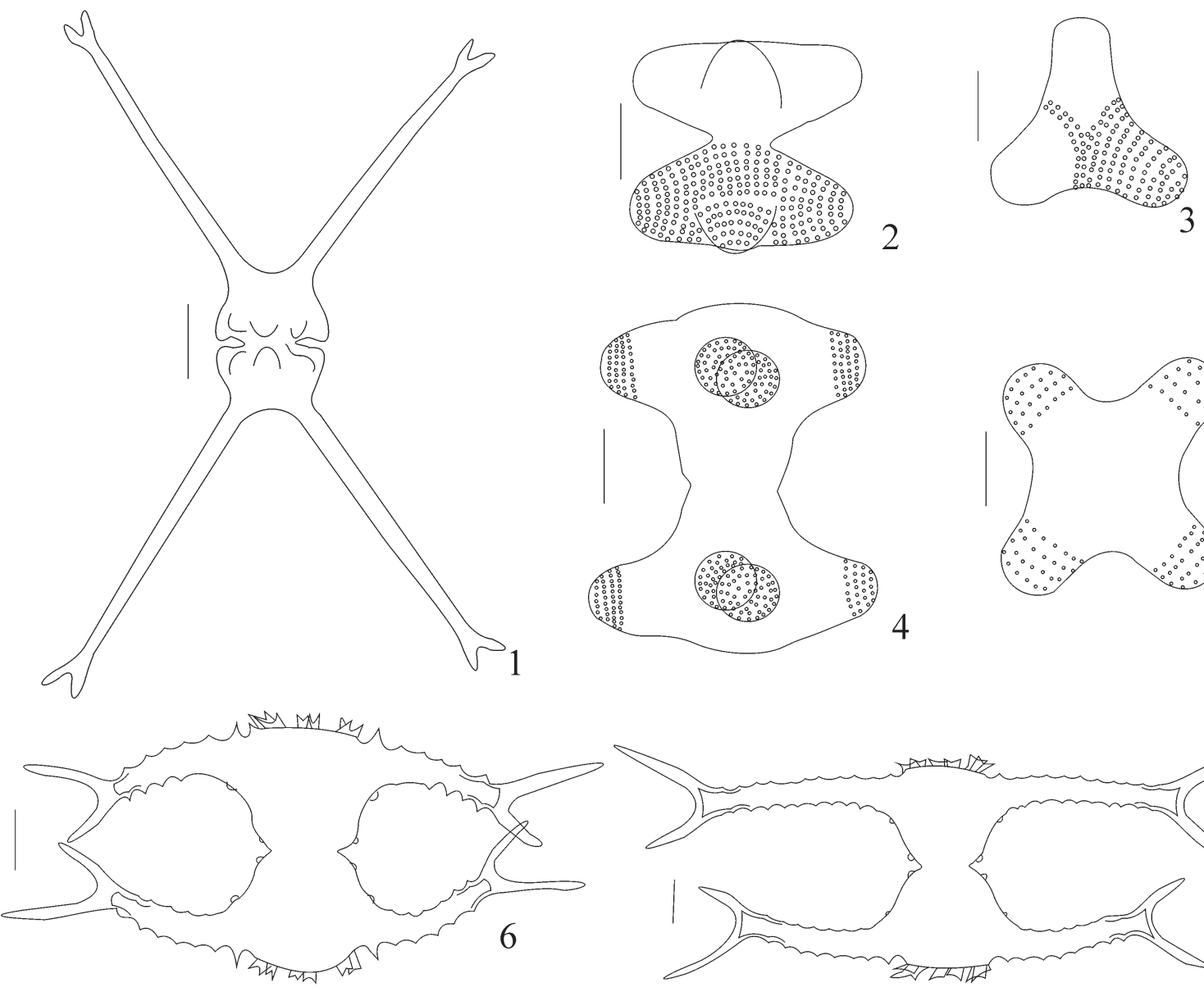

2
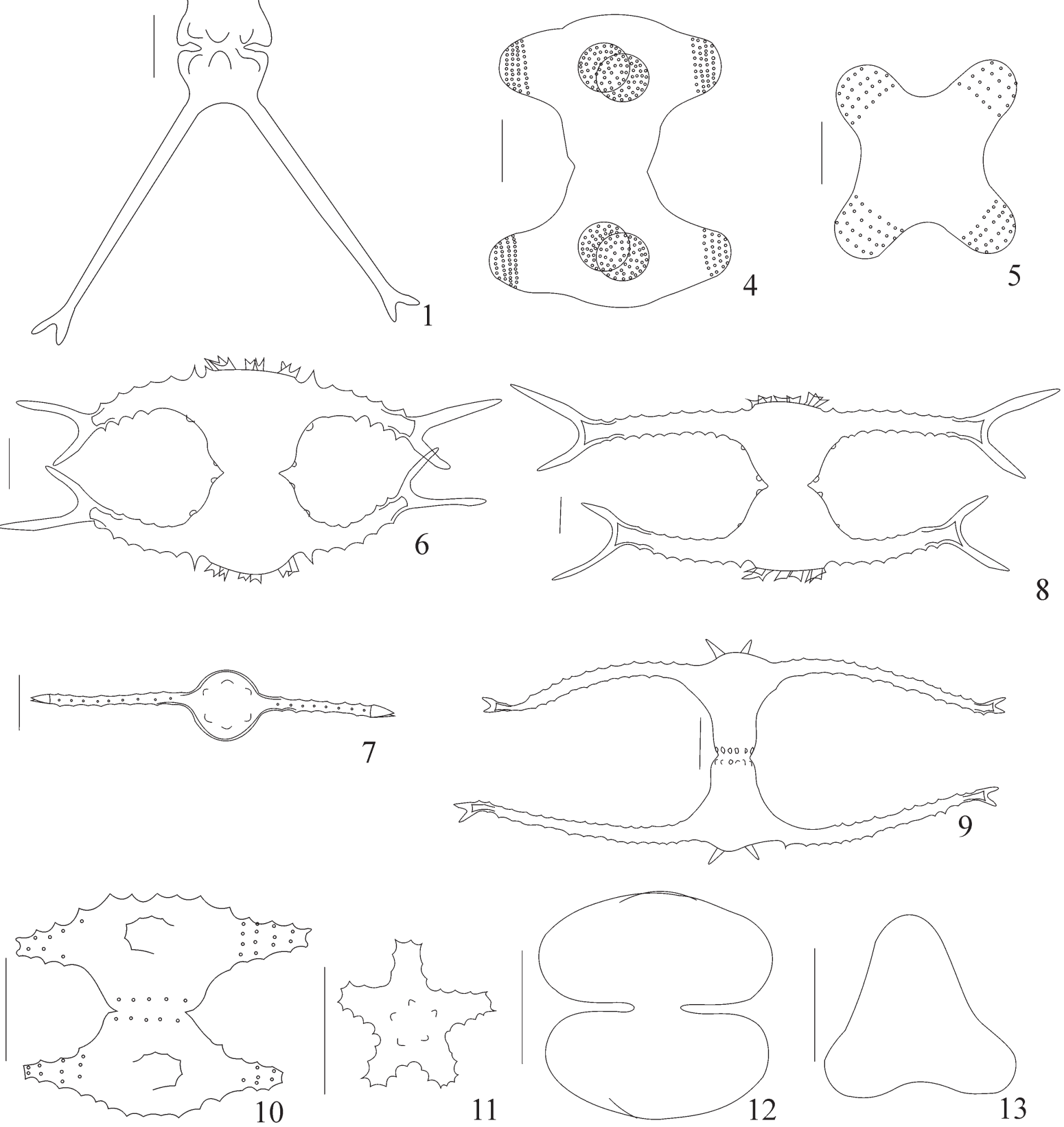

Figuras 1-13. Espécies de Staurastrum da lagoa do Caçó.1. Staurastrum columbetoides var. ginsbergeri. 2. S. dilatatum var. dilatatum f. dilatatum. 3. S. dilatatum var. dilatatum f. dilatatum, vista apical. 4. S. disputatum var. sinense. 5. S. disputatum var. sinense, vista apical. 6. S. cf. grallatorium. 7. S. cf. grallatorium, vista apical. 8. S. grallatorium var. brasiliense. 9. S. leptocladum var. cornutum. 10. S. margaritaceum var. margaritaceum. 11. S. margaritaceum var. margaritaceum, vista apical. 12. S. muticum var. muticum f. minus. 13 . S. muticum var. muticum f. minu, vista apical. Barras de escala $=10 \mu \mathrm{m}$. 
Primeiro registro de ocorrência no estado do Maranhão. Difere da variedade típica por apresentar os ângulos laterais mais pronunciados e pelas medidas celulares inferiores.

Staurastrum cf.grallatorium Nordst. var.grallatorium, Vid. Medd. Naturh. Foren. Kjöbenhavn (14/15): 228.1869.

\section{Figuras 6-7}

Células 1,3 a 1,9 vez mais longas que largas sem os processos; constrição mediana rasa, istmo em forma de "V"; semicélulas trapeziformes, margem apical elevada com uma série de 6 espinhos, margens laterais convexas divergindo para 2 longos processos convergentes, com margens crenuladas e furcado de tamanhos desiguais; vista apical fusiforme. Ccp = 41,5-53,5 $\mu \mathrm{m} ;$ Csp = 38,2-43,4 $\mu \mathrm{m} ; \mathrm{Lcp}=98,0-120,1$ $\mu \mathrm{m} ; \mathrm{Lsp}=19,9-34,0 \mu \mathrm{m} ; \mathrm{I}=9,2-13,0 \mu \mathrm{m}$.

Material estudado: BRASIL. MARANHÃO: Barreirinhas, Lagoa do Caçó, 14-IV-1999, M.J.Dellamano-Oliveira s.n.(SP336291); idem, 15-IV-1999, M.J.DellamanoOliveira s.n. (SP336292); idem, 17-IV-1999 M.J. Dellamano-Oliveira s.n. (SP336296); idem, 19-IV1999, M.J. Dellamano-Oliveira s.n. (SP336300).

Primeiro registro de ocorrência no estado do Maranhão. Os espécimes encontrados na lagoa do Caçó assemelham-se à variedade típica de $S$. grallatorium. Porém, a margem apical das semicélulas apresenta 6 espinhos e não 4 como citados em Prescott et al. (1982).

Staurastrum grallatorium Nordst. var. brasiliense (Grönb.) Förster., Amazoniana II(1/2): 83. 1969 三 S. saltans Josh. var. brasiliense Grönb., Acta Soc. Sci. Fennic. II, B, 2(6): 30. 1945.

Figura 8

Difere da variedade típica por possuir processos mais longos e dispostos horizontalmente e não convergentes como na variedade tipo. Ccp $=47,0-50,3$ $\mu \mathrm{m} ; \mathrm{Csp}=39,8-62,7 \mu \mathrm{m} ; \mathrm{Lcp}=109,1-128,5 \mu \mathrm{m} ; \mathrm{Lsp}$ $=18,3-27,0 \mu \mathrm{m} ; \mathrm{I}=6,1-13,0 \mu \mathrm{m}$.

Material estudado: BRASIL. MARANHÃO: Barreirinhas, Lagoa do Caçó, 12-IV-1999, M.J.Dellamano-Oliveira s.n. (SP336288); idem, 13-IV-1999, M.J.DellamanoOliveira s.n. (SP336289); idem, 14-IV-1999, M.J. Dellamano-Oliveira s.n. (SP336291); idem, 15-IV1999, M.J. Dellamano-Oliveira s.n. (SP336292); idem, 17-IV-1999, M.J. Dellamano-Oliveira s.n. (SP336296); idem, 22-XI-1999, M.J. DellamanoOliveira s.n. (SP336297); idem, 19-IV-1999, M.J. Dellamano-Oliveira s.n. (SP336300).

Primeiro registro de ocorrência no estado do Maranhão.

Staurastrum leptocladum Nordst. var. cornutum f. cornutum, Bih. Kongl. Svenska Vet. Akad. Handl. 8(18): 19. 1884.

Figuras 9, 46-47

Células 2,8-3,6 vezes mais longas que largas sem os processos; constrição mediana rasa, istmo em forma de "V"; semicélulas subcampanuladas, levemente inflada logo acima do istmo, margem apical convexa, com um par de espinhos, margens laterais levemente convexas divergindo em 2 longos processos convergentes, com ápices levemente voltados para cima, de margens crenuladas, 2-denteados; vista apical fusiforme. Csp = 33,6-47,4 $\mu \mathrm{m}$; $\mathrm{Lcp}=91,8-108,6 \mu \mathrm{m}$; Lsp = 9,2-16,8 $\mu \mathrm{m} ; \mathrm{I}=3,8-6,1 \mu \mathrm{m}$.

Material estudado: BRASIL. MARANHÃO: Barreirinhas, Lagoa do Caçó, 12-IV-1999, M.J.Dellamano-Oliveira s.n.(SP336288); idem, 13-IV-1999, M.J.DellamanoOliveira s.n. (SP336289); idem, 18-XI-1999, M.J. Dellamano-Oliveira s.n. (SP336291); idem, 14-IV1999, M.J. Dellamano-Oliveira s.n. (SP336292); idem, 15-IV-1999, M.J. Dellamano-Oliveira s.n. (SP336294); idem, 16-IV-1999, M.J. DellamanoOliveira s.n. (SP336294); idem, 17-IV-1999, M.J. Dellamano-Oliveira s.n. (SP336296); idem, 22-XI1999, M.J. Dellamano-Oliveira s.n. (SP336297).

Primeiro registro de ocorrência no estado do Maranhão. Esta variedade difere da típica pela orientação convergente dos processos que, na variedade típica, são divergentes.

Staurastrum margaritaceum (Ehr.) Ralfs var. margaritaceum, Brit. Desm., p. 134. 1848 三 Pentasterias margaritacea. Ehr., Infus.: 144. 1838.

Figuras 10-11

Células 2,5 a 2,8 vezes mais longas que largas sem os processos; constrição mediana rasa, istmo em forma de "V"; semicélulas subtrapeziformes, margem apical convexa, crenulada, processos curtos, obtusos, horizontais a levemente convergentes, face das $\mathrm{s}=$ 
21,4-22,9 $\mu \mathrm{m} ; \mathrm{Lcp}=18,3-22,9 \mu \mathrm{m} ; \mathrm{Lsp}=$ 7,6-9,2 $\mu \mathrm{m}$; $\mathrm{I}=5,3-6,9 \mu \mathrm{m}$.

Material estudado: BRASIL. MARANHÃO: Barreirinhas, Lagoa do Caçó, 13-IV-1999, M.J.Dellamano-Oliveira s.n.(SP336289); idem, 17-IV-1999, M.J.DellamanoOliveira s.n. (SP336296); idem, 22-XI-1999, M.J. Dellamano-Oliveira s.n. (SP336297).

Primeiro registro de ocorrência no estado do Maranhão.

Staurastrum muticum (Bréb.) Ralfs var. muticum f. minus Rabh., Flor. Europ. Algar., III, p. 200. 1868.

Figuras 12-13, 56

Células aproximadamente tão longas quanto largas; constrição mediana profunda, istmo linear abrindo para o ápice; semicélulas subreniformes; parede celular lisa; vista apical triangular, margens côncavas entre os lobos. $\mathrm{C}=18,2-21,4 \mu \mathrm{m} ; \mathrm{L}=18,3$ 22,5 $\mu \mathrm{m} ; \mathrm{I}=4,6-5,3 \mu \mathrm{m}$

Material estudado: BRASIL. MARANHÃo: Barreirinhas, Lagoa do Caçó, 12-IV-1999, M.J.Dellamano-Oliveira s.n. (SP336288); idem, 9- IV-1999, M.J.DellamanoOliveira s.n. (SP336300).

Primeiro registro de ocorrência da variedade no estado do Maranhão. A forma minus difere da forma típica pelas dimensões celulares inferiores: variedade tipo apresenta $\mathrm{C}=22-43,5 \mu \mathrm{m}, \mathrm{L}=21-37,5 \mu \mathrm{m}$ e I $=7,5-12 \mu \mathrm{m}$.

\section{Staurastrum novae-caesareae Wolle var. brasiliense}

(Grönb.) Förster, Amazoniana, II(1/2): 89. 1969 三 S. pulcherrimum Cushman var. brasiliense Grönb., Acta Soc. Sci. Fennic. II, B, 2(6): 29. 251-252. 1945.

Figuras 14-15

Células ca. 1,3 vez mais longas que largas sem os processos; constrição mediana moderada, istmo aberto em forma de "U"; semicélulas aproximadamente oblongas, margem apical reta, margens laterais convexas convergindo para os ângulos apicais que terminam em 4 longos espinhos, margens basais côncavas; face das semicélulas com 5 séries de grânulos arranjados aos pares; vista apical 4-angular, margens retilíneas entre os ângulos. Ccp $=$ ca. 68,0 $\mu \mathrm{m} ; \mathrm{Csp}=$ ca. $49,7 \mu \mathrm{m} ; \mathrm{Lsp}=$ ca. $36,7 \mu \mathrm{m}, \mathrm{I}=$ ca. $18,3 \mu \mathrm{m}$.
Material estudado: BRASIL. MARANHÃO: Barreirinhas, Lagoa do Caçó, 12-IV-1999, M.J.Dellamano-Oliveira s.n. (SP336288).

Primeiro registro de ocorrência no estado do Maranhão. A variedade típica difere da var. brasiliense por possuir semicélulas elípticas, istmo em forma de "V" e processos dispostos horizontalmente.

Staurastrum rotula var. rotula Nordst., Vid. Medd. Naturh. Foren. Kjöbenhavn: 227. 1869.

Figuras 16-17

Células ca. 1,6 vez mais longas que largas sem os processos; constrição mediana rasa, istmo amplamente aberto; semicélulas hexagonais terminando em longos processos, geralmente paralelos, com as margens nodulosas, às vezes levemente curvos e 3 -espinados, face das semicélulas lisa, margem apical convexa com uma série intramarginal de verrugas, margem basal, levemente côncava; vista apical 7-angular, margens entre os processos amplamente côncavas, região mediana com uma série circular de verrugas. Csp = ca. 32,1 $\mu \mathrm{m} ; \mathrm{Lcp}=$ ca. 58,1 $\mu \mathrm{m}$; Lsp = ca. 19,9 $\mu \mathrm{m}$; $\mathrm{I}=$ ca. $10,2 \mu \mathrm{m}$.

Material estudado: BRASIL. MARANHÃo: Barreirinhas, Lagoa do Caçó, 12-IV-1999, M.J.Dellamano-Oliveira s.n.(SP336288); idem, 13-IV-1999, M.J.DellamanoOliveira s.n., (SP336289).

Registrado por Araújo (2000) para o estado do Maranhão nas lagoas do Parque Nacional dos Lençóis Maranhenses.

Staurastrum steliferum Borge var. steliferum, Ark. f. Bot. 19(17): 42.1925.

Figuras 18-19

Células 1,7 - 2 vezes mais longas que largas sem os processos; constrição mediana rasa, istmo em forma de "V"; semicélula em forma de sino invertido, face das semicélulas com espinhos, margem apical quase reta, margens laterais côncavas divergindo para os processos 3-espinados situados nos ângulos apicais, margem basal das semicélulas com uma fileira de pequenos espinhos próximos ao istmo; base dos processos com 2 espinhos de cada lado e ápice dos processos 5-denteado; vista apical 4-angular, margens côncavas entre os processos. Ccp $=83,4-128,5 \mu \mathrm{m}$; Csp = 30,6-38,2 $\mu \mathrm{m} ; \mathrm{Lcp}=76,5-127,0 \mu \mathrm{m} ; \mathrm{Lsp}=$ 15,3-22,9 $\mu \mathrm{m} ; \mathrm{I}=9,0-13,8 \mu \mathrm{m}$. 

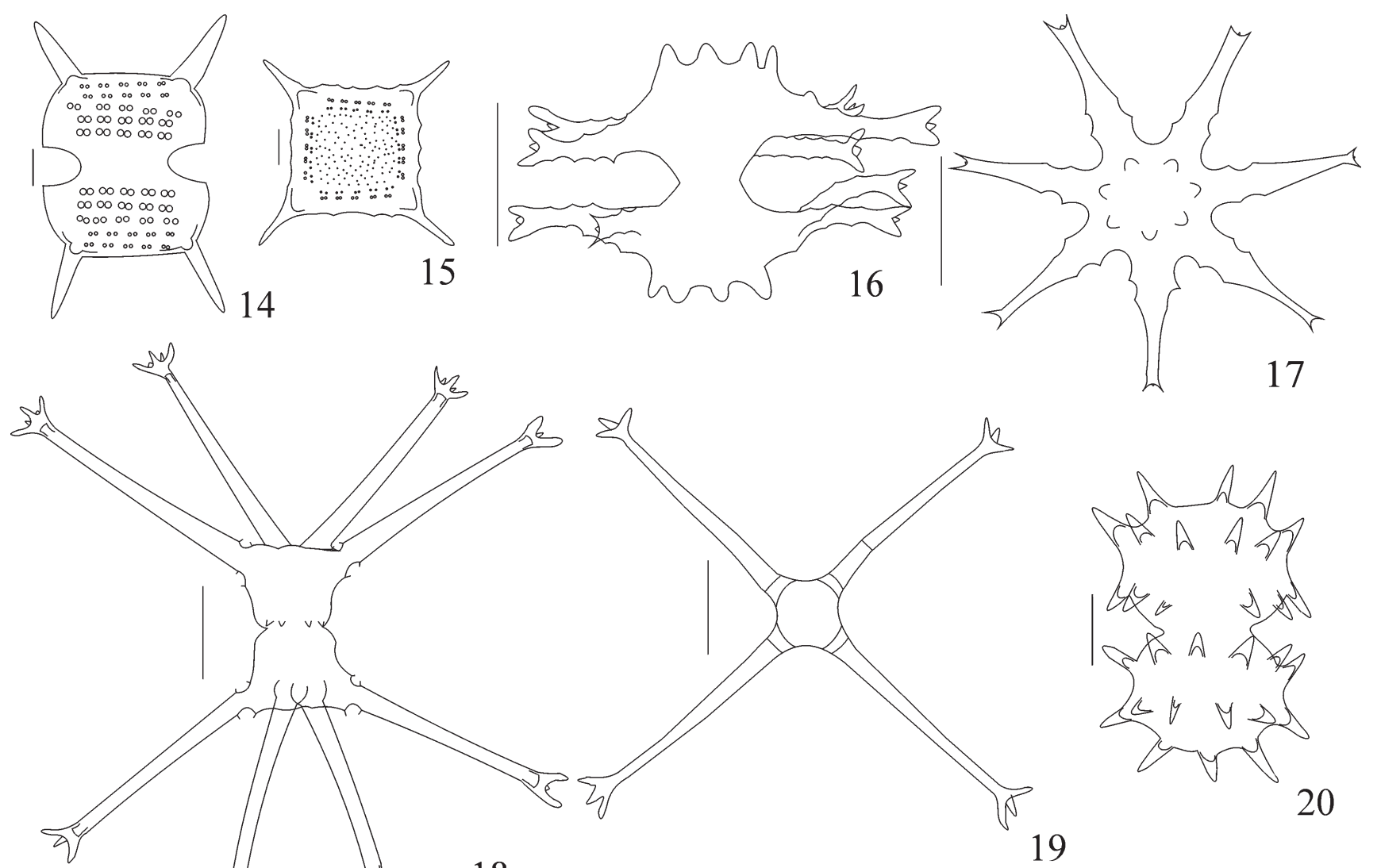

18

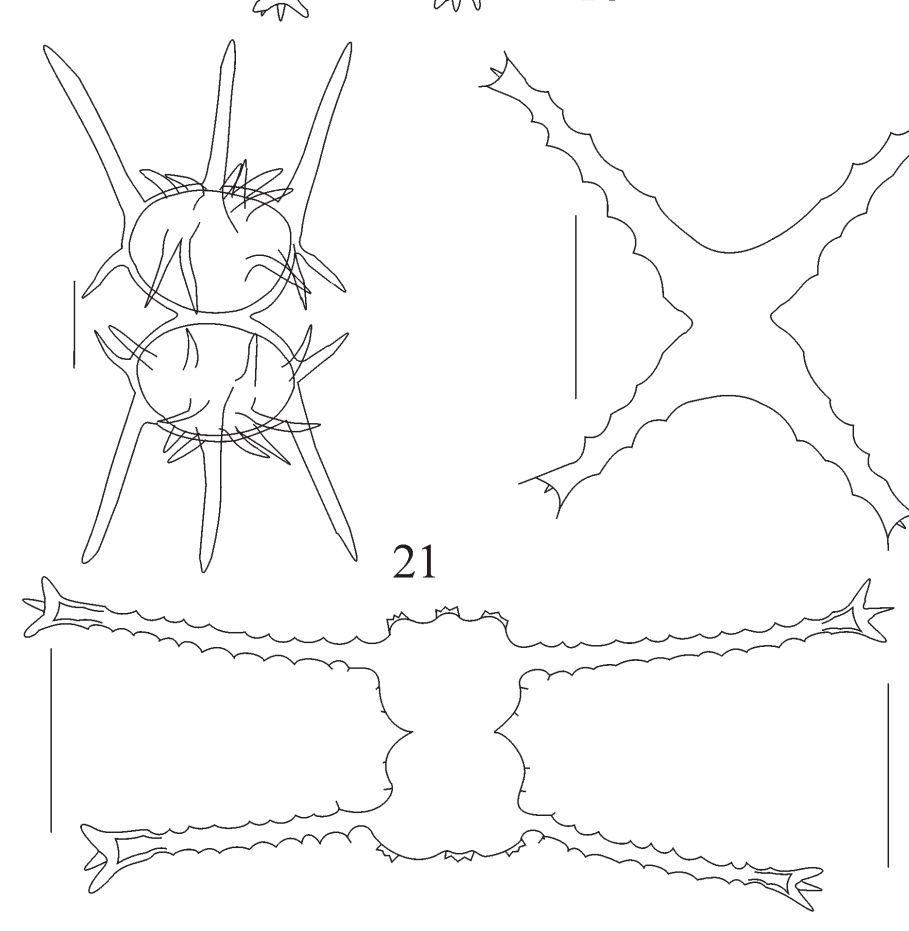

22

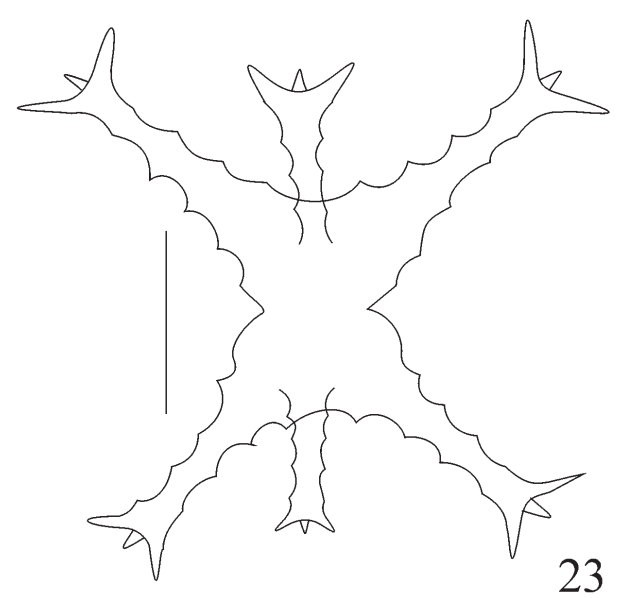

23

24

Figuras 14-25. Espécies de Staurastrum da lagoa do Caçó. 14. Staurastrum novae-caesarae var. brasiliense. 15. Staurastrum novae-caesarae var. brasiliense, vista apical. 16. S. rotula. 17. S. rotula, vista apical. 18. S. steliferum var. steliferum. 19. S. steliferum var. steliferum, vista apical. 20. S. steliferum var. grönbladii. 21. S. tentaculiferum. 22. S. tetracerum var. tetracerum f. tetracerum. 23. S. tetracerum var. tetracerum f. trigona. 24. S. triundulatum var. floridense. 25. S. triundulatum var. floridense, vista apical. Barras de escala $=10 \mu \mathrm{m}$. 
Material estudado: BRASIL. MARANHÃO: Barreirinhas, Lagoa do Caçó, 12-IV-1999, M.J.Dellamano-Oliveira s.n.(SP336288); idem, 13-IV-1999, M.J.DellamanoOliveira s.n. (SP336289); idem, 18-XI-1999, M.J. Dellamano-Oliveira s.n. (SP336290); idem, 14-IV1999, M.J. Dellamano-Oliveira s.n. (SP336292); idem, 15-IV-1999, M.J. Dellamano-Oliveira s.n. (SP336291); idem, 20-XI-1999, M.J. DellamanoOliveira s.n. (SP336293); idem, 21-XI-1999, M.J. Dellamano-Oliveira s.n. (SP336295); idem, 17-IV1999, M.J. Dellamano-Oliveira s.n. (SP336296); idem, 22-XI-1999, M.J. Dellamano-Oliveira s.n. (SP336297); idem, 24-XI-1999, M.J. DellamanoOliveira s.n. (SP336299).

Primeiro registro de ocorrência no estado do Maranhão.

Staurastrum teliferum Ralfs var. groenbladii Förster, Hydrobiol. 23(3/4): 429. 1964.

Figuras 20, 48

Células ca. 1,7 vez mais longas que largas sem os espinhos; constrição mediana rasa, istmo aberto em forma de "V"; semicélulas elípticas a semicirculares recobertas por espinhos, com 3 na margem apical, 2 espinhos em cada margem lateral e 2 séries horizontais de 4 espinhos cada, na face das semicélulas; vista apical 3-angular com margens retas a levemente convexas e pólos arredondados, com 12 espinhos na borda e 6 espinhos intramarginais. Cce $=43,6-46,5$ $\mu \mathrm{m} ; \mathrm{Cse}=32,1-36,7 \mu \mathrm{m} ; \mathrm{Lce}=27,5-29,1 \mu \mathrm{m} ; \mathrm{Lse}=$ $18,9-21,5 \mu \mathrm{m} ; \mathrm{I}=8,2-10,7 \mu \mathrm{m}$.

Material estudado: BRASIL. MARANHÃO: Barreirinhas, Lagoa do Caçó, 12-IV-1999, M.J.Dellamano-Oliveira s.n.(SP336288); idem, 13-IV-1999, M.J.DellamanoOliveira s.n (SP336289); idem, 17-IV-1999, M.J. Dellamano-Oliveira s.n (SP336296); idem, 18-IV1999, M.J. Dellamano-Oliveira s.n (SP336298); idem, 19-IV-1999, M.J. Dellamano-Oliveira s.n (SP336300).

Registrado por Araújo (2000) nas lagoas do Parque Nacional dos Lençóis Maranhenses, estado do Maranhão. A variedade típica difere da var. grönbladii pelo padrão de distribuição dos espinhos na face das semicélulas, apresentando um arco de espinhos sobre a região mediana e um espinho intramarginal entre os ângulos basal e apical.
Staurastrum teliferum Ralfs cf. var. pecten (Perty) Grönb., Acta Soc. Sci. Fennic. II, B, 2(6): 31. 1945 Phycastrum ectin Perty, Kleinst. Lebensf: 210. 1852.

Células tão longas quanto largas sem os espinhos, semicélulas amplamente elípticas, vista apical com margens retusas. $\mathrm{Cce}=$ ca. 38,7 $\mu \mathrm{m} ; \mathrm{Cse}=$ ca. 21,6 $\mu \mathrm{m} ;$ Lse = ca. 18,6 $\mu \mathrm{m} ; \mathrm{I}=$ ca. 7,5 $\mu \mathrm{m}$.

Material estudado: BRASIL. MARANHÃO: Barreirinhas, Lagoa do Caçó, 21-XI-1999, M.J.Dellamano-Oliveira s.n. (SP336295).

Primeiro registro de ocorrência da variedade no estado do Maranhão. Como foram encontrados poucos espécimes na lagoa do Caçó, foi difícil observar e registrar a decoração da face das semicélulas. Além disso, a vista apical apresentou margens levemente retusas e não retas como consta em Prescott et al. (1982).

Staurastrum tentaculiferum Borge var.tentaculiferum,

Bih. Kongl. Svenska Vet. Akad. Handl. 24, Afd. III (12): 31.1899.

Figura 21

Células ca. 1,5 vez mais longas que largas sem os processos; constrição mediana rasa, istmo aberto; semicélulas elípticas; ângulos apicais terminando em 3 longos processos voltados verticalmente; face das semicélulas e margem apical com 6 longos espinhos; vista apical não observada. $\mathrm{Ccp}=\mathrm{ca} \cdot 61,9 \mu \mathrm{m} ; \mathrm{Csp}=$ ca. 32,0 $\mu \mathrm{m} ; \mathrm{Lcp}=$ ca. $35,2 \mu \mathrm{m} ; \mathrm{Lsp}=$ ca. $21,4 \mu \mathrm{m}$; $\mathrm{I}=$ ca. $9,0 \mu \mathrm{m}$.

Material estudado: BRASIL. MARANHÃO: Barreirinhas, Lagoa do Caçó, 17-IV-1999, M.J.Dellamano-Oliveira s.n.(SP336296); idem, 19-IV-1999, M.J.DellamanoOliveira s.n. (SP336300).

Primeiro registro de ocorrência no estado do Maranhão.

Staurastrum tetracerum Ralfs var. tetracerum $\mathrm{f}$. tetracerum, Ann. Mag. Nat. Hist. 15: 150. 1845.

Figuras 22, 57

Células aproximadamente tão longas quanto largas sem os processos; constrição mediana moderada, istmo em forma de "V"; semicélulas trapeziformes, ângulos apicais prolongados em 2 longos processos 
crenulados, 3-denteados, margem apical côncava, lisa; vista apical 2-angular. Csp = 7,6-10,7 $\mu \mathrm{m} ; \mathrm{Lcp}=30,6-$ $32,6 \mu \mathrm{m} ; \mathrm{Lsp}=6,6-9,9 \mu \mathrm{m} ; \mathrm{I}=3,5-5,3 \mu \mathrm{m}$.

Material estudado: BRASIL. MARANHÃO: Barreirinhas, Lagoa do Caçó, 12-IV-1999, M.J.Dellamano-Oliveira s.n.(SP336288); idem, 13-IV-1999, M.J.DellamanoOliveira s.n. (SP336289); idem, 15-IV-1999, M.J. Dellamano-Oliveira s.n. (SP336292); idem, 17-IV1999, M.J. Dellamano-Oliveira s.n. (SP336296).

Primeiro registro de ocorrência no estado do Maranhão.

Staurastrum tetracerum Ralfs var. tetracerum f. trigona Lund., Nova Acta Reg. Soc. Sci. Upsal., III, 8: 69. 1871.

Figura 23

Células 1,1-1,2 vez mais longas que largas sem os processos; constrição mediana moderada, istmo em forma de "V"; semicélulas trapeziformes, ângulos apicais prolongados em 3 processos crenulados, 3-denteados, margem apical côncava, crenuladas; vista apical 3-angular.

$\mathrm{Ccp}=26,4-27,5 \mu \mathrm{m} ; \mathrm{Csp}=12,2-13,4 \mu \mathrm{m} ; \mathrm{Lcp}=$ 22,9-25,5 $\mu \mathrm{m} ; \mathrm{Lsp}=10,7 \mu \mathrm{m} ; \mathrm{I}=4,6-5,7 \mu \mathrm{m}$.

Material estudado: BRASIL. MARANHÃO: Barreirinhas, Lagoa do Caçó, 12-IV-1999, M.J.Dellamano-Oliveira s.n.(SP336298); idem, 18-XI-1999, M.J.DellamanoOliveira s.n. (SP336290).

Primeiro registro de ocorrência no estado do Maranhão.

Staurastrum triundulatum Borge var. floridense Scott \& Grönb., Acta Soc. Sci. Fennic. II, B. 8: 47. 1957.

Figuras 24-25, 43-44

Células ca. 2 vezes mais longas que largas sem os processos; constrição mediana rasa, istmo em forma de "V"; semicélulas sub-retangulares, margens apicais retas com 3 verrugas intramarginais, margens laterais terminando em 2 longos processos, quase horizontais, 3-denteados, crenulados, levemente divergentes, face das semicélulas lisa; vista apical fusiforme, inflada de cada lado da região mediana, com 2 séries de 3 verrugas intramarginais 3-denteadas. Csp $=25,2-30,6$ $\mu \mathrm{m} ; \mathrm{Lcp}=73,4-95,6 \mu \mathrm{m} ; \mathrm{Lsp}=12,2-15,3 \mu \mathrm{m} ; \mathrm{I}=$ $6,1-8,9 \mu \mathrm{m}$.
Material estudado: BRASIL. MARANHÃO: Barreirinhas, Lagoa do Caçó, 12-IV-1999, M.J. Dellamano-Oliveira s.n.(SP336288); idem, 13-IV-1999, M.J.DellamanoOliveira s.n. (SP336289); idem, 15-IV-1999, M.J. Dellamano-Oliveira s.n. (SP 3362920); idem, 17IV-1999, M.J. Dellamano-Oliveira s.n. (SP336296); idem, 22-XI-1999, M.J. Dellamano-Oliveira s.n. (SP336297); idem, 19-IV-1999, M.J. DellamanoOliveira s.n. (SP336300).

Primeiro registro de ocorrência no estado do Maranhão. Difere da variedade típica por apresentar três verrugas intramarginais na margem apical das semicélulas e pela região basal das semicélulas que é mais inflada do que a variedade típica, conforme Prescott et al. (1982).

Staurastrum vestitum Ralfs var. subanatinum West \& West, Trans. Royal Irish Acad. 32B (1): 54. 1902.

Figuras 26-27, 45

Células ca. 1,2 vez mais longas que largas sem os processos; constrição mediana rasa, istmo aberto; semicélulas elíptico-fusiformes, face das semicélulas com duas fileiras de grânulos, margem apical convexa provida com uma série de verrugas 2-denteadas, margem basal convexa, ângulos apicais se estendendo em 2 processos quase horizontais, 3-denteados; vista apical 3-angular, margens retas entre os processos, com 2 verrugas proeminentes e com uma série de 5 a 6 verrugas intra-marginais de cada lado. $\mathrm{Csp}=$ ca. $36,7 \mu \mathrm{m} ; \mathrm{Lcp}=$ ca. 85,7 $\mu \mathrm{m} ; \mathrm{Lsp}=$ ca. 30,6 $\mu \mathrm{m} ; \mathrm{I}=$ ca. $13,8 \mu \mathrm{m}$.

Material estudado: BRASIL.MARANHÃO: Barreirinhas, Lagoa do Caçó, 13-IV-1999, M.J. DellamanoOliveira s.n. (SP336289); idem, 16-IV-1999, M.J. Dellamano-Oliveira s.n. (SP336294); idem, 18-IV1999, M.J. Dellamano-Oliveira s.n. (SP336298); idem, 19-IV-1999, M.J. Dellamano-Oliveira s.n. (SP336300).

Primeiro registro de ocorrência no estado do Maranhão. Esta variedade difere da típica por possuir processos mais longos, com os dentes da extremidade dos processos mais robustos e por apresentar verrugas apicais pouco desenvolvidas. 


\section{Staurodesmus Teiling}

Chave para identificação dos táxons de Staurodesmus encontrados na lagoa do Caçó

1. Ângulos apicais prolongados em 2 espinhos

2. Semicélulas trapeziformes S. tortus

2. Semicélulas triangulares, elípticas, subtrapeziformes

3. Espinhos dispostos horizontalmente ou levemente divergentes

S. indentatus

3. Espinhos dispostos diagonalmente

4. Células 1,3 vezes mais longas que largas; cloroplasto com 1 pirenóide ..... S. validus var. validus

4. Células isodiamétricas; cloroplasto com 2 pirenóides

1. Ângulos apicais prolongados em 3 espinhos

5. Istmo alongado, cilíndrico

S. mamillatus

5. Istmo aberto

6. Células tão longas quanto largas S. dejectus var. borealis f. amazonensis

6. Células $1,2 \mathrm{vez}$ mais longas que largas

7. Semicélulas elípticas em vista frontal S. megacanthus var. minus

7. Semicélulas trapeziformes em vista frontal S. connatus

Staurodesmus connatus (Lund.) Thom. var. connatus, Nova Acta Reg. Soc. Sci. Upsal., IV, 17 (12): 34. $1960 \equiv$ Staurastrum dejectum Bréb. var. connatum Lund., Nova Acta Reg. Soc. Sci. Upsal.: 60. 1871.

Figuras 28-29, 58-59

Células ca. 1,2 vez mais longas que largas sem os espinhos; constrição mediana rasa, istmo aberto; semicélulas trapeziformes, margem apical truncada, ângulos apicais terminando em espinhos diagonais, margens laterais convexas; vista apical 3-angular, com as margens retusas entre os espinhos. Cce $=21,4-27,5$ $\mu \mathrm{m} ; \mathrm{Cse}=17,9-20,6 \mu \mathrm{m} ;$ Lce $=22,9-29,1 \mu \mathrm{m} ;$ Lse $=$ $15,0-16,8 \mu \mathrm{m} ; \mathrm{I}=4,6-6,4 \mu \mathrm{m}$.

Material estudado: BRASIL.MARANHÃO: Barreirinhas, Lagoa do Caçó, 12-IV-1999, M.J.Dellamano-Oliveira s.n. (SP336288); idem, 13-IV-1999, M.J.DellamanoOliveira s.n. (SP336289); idem, 18-IV-1999, M.J. Dellamano-Oliveira s.n. (SP336298).

Primeiro registro de ocorrência no estado do Maranhão.

Staurodesmus dejectus (Bréb. ex Ralfs) Teil. var. borealis Croasd. f. amazonensis Förster, Amazoniana 2 (1/2): 68. 1969.

Figuras 30-31

Células tão longas quanto largas sem os espinhos; constrição mediana profunda, istmo aberto; semicélulas triangulares, margem apical inflada na região mediana, ângulos apicais terminando em longos espinhos levemente divergentes; vista apical 3-angular, com as margens infladas na região mediana. $\mathrm{Cc}=21,4-44,4$ $\mu \mathrm{m} ;$ Cse $=18,3-35,3 \mu \mathrm{m} ;$ Lce $=27,5-80,6 \mu \mathrm{m} ;$ Lse $=$ 17,6-37,8 $\mu \mathrm{m} ; \mathrm{I}=4,6-9,6 \mu \mathrm{m}$.

Material estudado: BRASIL. MARANHÃO: Barreirinhas, Lagoa do Caçó, 12-IV-1999, M.J.Dellamano-Oliveira s.n.(SP336288); idem, 13-IV-1999, M.J.DellamanoOliveira s.n. (SP336289); idem, 14-IV-1999, M.J. Dellamano-Oliveira s.n. (SP336291); idem, 15-IV1999, M.J. Dellamano-Oliveira s.n. (SP336292); idem, 17-IV-1999, M.J. Dellamano-Oliveira s.n. (SP336296).

Primeiro registro de ocorrência no estado do Maranhão. Difere da variedade e forma típica por apresentar dimensões celulares maiores, pelo ápice distintamente convexo, robusto e pelos espinhos mais divergentes.

Staurodesmus indentatus (West) Teil. var. indentatus, Bot. Notiser (1): 64.1948 = Arthrodesmus incus Hass. var. indentatus West \& West, Ray Soc. London: 94. 1912.

Figura 32

Células 1,3-1,5 vez mais longas que largas sem os espinhos; constrição mediana profunda, istmo aberto; semicélulas triangulares, margem apical retusa, margens laterais quase retas, terminando em 2 longos 
espinhos quase horizontais a levemente divergentes; vista apical não observada. Cce $=16,8-28,9 \mu \mathrm{m}$; Cse $=18,3-18,8 \mu \mathrm{m} ;$ Lce $=44,4-45,0 \mu \mathrm{m} ;$ Lse $=12,2-13,8$ $\mu \mathrm{m} ; \mathrm{I}=3,9-4,3 \mu \mathrm{m}$.

Material estudado: BRASIL. MARANHÃO: Barreirinhas, Lagoa do Caçó, 16-IV-1999, M.J.Dellamano-Oliveira s.n. (SP336294).

Primeiro registro de ocorrência no estado do Maranhão.

Staurodesmus mamillatus (Nordst.) Teil. var. mamillatus, Ark. f. Bot. 6(11): 536. $1967 \equiv$ Staurastrum mamillatum Nordst. Vid. Medd. Naturh. Foren. Kjöbenhavn (14/15): 225. 1869.

Figuras 33-34

Células ca. 1,5 vez mais longas que largas sem os espinhos; constrição mediana profunda, istmo alongado cilíndrico; semicélulas triangulares, margem apical reta ou convexa, margens laterais convexas, ângulos apicais arredondados, terminando em espinho divergente; vista apical 3-angular, com margens retas entre os espinhos. Cce $=$ ca. 24,8 $\mu \mathrm{m} ;$ Cse = ca. 27,9 $\mu \mathrm{m} ;$ Lce $=$ ca. 50,5 $\mu \mathrm{m} ;$ Lse = ca. 18,6 $\mu \mathrm{m} ; \mathrm{I}=$ ca. $6,2 \mu \mathrm{m}$.

Material estudado: BRASIL. MARANHÃO: Barreirinhas, Lagoa do Caçó, 20-XI-1999, M.J.Dellamano-Oliveira s.n. (SP336293).

Primeiro registro de ocorrência no estado do Maranhão.

Staurodesmus megacanthus (Lund) Thunm. var. minus Hir., Men. Coll. Sci. Univ. Kyoto, B, 19: 68. 1948.

Figura 35

Células ca. 1,2 vez mais longas que largas sem os espinhos; constrição mediana profunda, istmo aberto; semicélulas elípticas, margens apicais e laterais convexas, ângulos apicais arredondados terminando em um espinho curto e robusto, quase horizontal; vista apical não observada. $\mathrm{C}=$ ca. 23,9 $\mu \mathrm{m} ; \mathrm{L}=$ ca. 20,4 $\mu \mathrm{m} ; \mathrm{I}=$ ca. 6,0 $\mu \mathrm{m}$.

Material estudado: BRASIL. MARANHÃO: Barreirinhas, Lagoa do Caçó, 13-IV-1999, M.J.Dellamano-Oliveira s.n. (SP336289).

Primeiro registro de ocorrência no estado do Maranhão. Difere da variedade típica pelas medidas inferiores.
Staurodesmus tortus (Grönb.) Teil. var. tortus, Ark. f. Bot., II, 6(11): 546.1967 = Arthrodesmus tortus Grönb., Mem. Soc. Fauna Flora Fennic. 28 (19511952). 1953.

Figura 36

Células torcidas 0,9-1,3 vez mais longas que largas sem os espinhos; constrição mediana profunda, istmo aberto; semicélulas trapeziformes, margem apical retusa, ângulos apicais pontiagudos terminando em espinho reto e divergente, margens basais retas a levemente convexas; vista apical 2-angular. Cce =

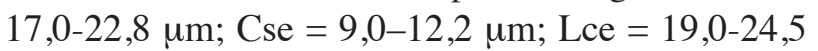
$\mu \mathrm{m} ; \mathrm{Lse}=7,0-13,8 \mu \mathrm{m} ; \mathrm{I}=4,6-6,4 \mu \mathrm{m}$.

Material estudado: BRASIL. MARANHÃO: Barreirinhas, Lagoa do Caçó, 13-IV-1999, M.J.Dellamano-Oliveira s.n.(SP336289); idem, 14-IV-1999, M.J.DellamanoOliveira s.n. (SP336291); idem, 16 - IV- 1999, M.J. Dellamano-Oliveira s.n. (SP336294); idem, 17-IV1999, M.J. Dellamano-Oliveira s.n. (SP336296); idem, 18-IV-1999, M.J. Dellamano-Oliveira s.n. (SP336298); idem, 19-IV-1999, M.J. DellamanoOliveira s.n. (SP336300).

Primeiro registro de ocorrência no estado do Maranhão.

Staurodesmus validus (West \& West) Thom. var. validus, Nova Acta Reg. Soc. Sci. Upsal., 17(12): 35. 1960 = Arthrodesmus incus (Bréb.) Hass. var. validus West \& West, Linn. Soc. Jour. Bot. 33: 320. 1898.

Figura 37

Células ca. 1,3 vez mais longa que larga sem os espinhos; constrição mediana profunda, istmo aberto; semicélulas subtrapeziformes, com margens convexas, ângulos apicais terminando em longo espinho divergente; vista apical e lateral não observadas; cloroplasto com 1 pirenóide. $\mathrm{Cce}=62,7 \mu \mathrm{m} ; \mathrm{Cse}=$ $36,7 \mu \mathrm{m} ;$ Lce $=70,4-78,0 \mu \mathrm{m} ;$ Lse $=27,5-28,3 \mu \mathrm{m}$; $\mathrm{I}=8,1-8,9 \mu \mathrm{m}$.

Material estudado: BRASIL. MARANHÃO: Barreirinhas, Lagoa do Caçó, 17-IV-1999, M.J.Dellamano-Oliveira s.n. (SP336296).

Primeiro registro de ocorrência no estado do Maranhão.

Staurodesmus validus (West \& West) Thom. var. subvalidus (Grönb.) Teil., Ark. F. Bot., II, 6 (11): 
$566.1967 \equiv$ Arthrodesmus subvalidus Grönb.,Acta

Soc. Sci. Fennic. II, B, 2(6): 24. 1945.

Figura 38

Células aproximadamente isodiamétricas; constrição mediana profunda, istmo aberto; semicélulas subtrapeziformes, com margens convexas, ângulos apicais terminando em espinho divergente; cloroplasto com 2 pirenóides. Cce $=41,3-53,1 \mu \mathrm{m}$; Cse $=39,8$ $53,1 \mu \mathrm{m} ;$ Lce $=56,6-61,2 \mu \mathrm{m} ;$ Lse $=29,1-1,3 \mu \mathrm{m} ; \mathrm{I}$ $=7,6 \mu \mathrm{m}$.

Material estudado: BRASIL. MARANHÃO: Barreirinhas, Lagoa do Caçó, 12-IV-1999, M.J.Dellamano-Oliveira s.n. (SP336288).

Registrado por Araújo (2000) no estado do Maranhão. Difere da variedade típica pelas células aproximadamente isodiamétricas e por possuir dois pirenóides por semicélula.

\section{Xanthidium Ehrenberg emend. Ralfs}

Chave para identificação dos táxons de Xanthidium encontrados na lagoa do Caçó

1. Semicélulas trapeziformes em vista

frontal X. cf. eckertii

1. Semicélulas hexagonais ou elípticohexagonais em vista frontal

2. Margem apical das semicélulas côncava .......................................... fragile

2. Margem apical das semicélulas convexa ....................................... regulare

Xanthidium cf. eckertii Förster var. eckertii, Hydrobiol. 23(3/4): 410. 1964.

Figuras 39, 53, 60

Células 1,2-1,4 vez mais longas que largas sem os espinhos; constrição mediana profunda, istmo linear abrindo para os ápices; semicélulas trapeziformes, margem apical reta a levemente convexa, ângulos apicais e basais arredondados, margens laterais convexas recobertas por espinhos, 3 em cada margem lateral e 4 na margem apical, face das semicélulas providas de 2 grandes papilas centrais circundadas por papilas menores; vista apical não observada. Cce = 67,3-69,6 $\mu \mathrm{m} ;$ Cse $=56,6-58,9 \mu \mathrm{m} ;$ Lce $=52,0-55,167,3$ $\mu \mathrm{m} ; \mathrm{Lse}=40,3-48,9 \mu \mathrm{m} ; \mathrm{I}=10,7-18,3 \mu \mathrm{m}$.

Material estudado: BRASIL. MARANHÃO: Barreirinhas, Lagoa do Caçó, 13-IV-1999, M.J.Dellamano-Oliveira
s.n.(SP336289); idem,15-IV-1999, M.J.DellamanoOliveira s.n. (SP336292).

Primeiro registro de ocorrência no estado do Maranhão. Nos espécimes da lagoa do Caçó, não foi observada a vista apical, o que nos levou a manter o material estudado como $X$. cf. eckertii.

Xanthidium fragile Borge var. fragile, Bih. Kongl. Svenska Vet. Akad. Handl., 24 Afd. III (12): 17. 1899.

Figuras 40, 49

Células 1,5 - 1,6 vez mais longas que largas sem os espinhos; constrição mediana profunda, istmo agudo e aberto; semicélulas hexagonais, margens apical e laterais côncavas, margens basais convexas com um pequeno espinho central em cada ângulo, série inferior de 6 ângulos e superior de 4, todos terminando em espinhos curtos, grosseiros, desiguais e divergentes, frequentemente curvos; vista apical não observada; parede celular lisa. Cce $=90,2-108,5$ $\mu \mathrm{m} ;$ Cse $=62,7-73,4 \mu \mathrm{m} ;$ Lce $=67,3-81,8 \mu \mathrm{m} ;$ Lse $=$ $42,1-45,1 \mu \mathrm{m} ; \mathrm{I}=22,5-25,2 \mu \mathrm{m}$.

Material estudado: BRASIL.MARANHÃO: Barreirinhas, Lagoa do Caçó, 12-IV-1999, M.J.Dellamano-Oliveira s.n. (SP336288); idem, 17-IV-1999, M.J.DellamanoOliveira s.n. (SP336293); idem, 20-XI-1999, M.J. Dellamano-Oliveira s.n. (SP336296).

Primeiro registro de ocorrência no estado do Maranhão.

Xanthidium regulare Nordst., Vidensk. Meddr. Dansk naturh. Foren. 1869 (14-15): 231. 1870.

Figuras 41-42, 51-52

Células 1,6 - 1,8 vez mais longa que larga sem os espinhos; constrição mediana moderada, istmo agudo e aberto; semicélulas hexagonais, margens basais convexas, ângulos apicais e laterais terminando em espinhos curtos e grosseiros; vista apical 6-angular; parede celular lisa. Cce $=19,9-34,1 \mu \mathrm{m}$; Cse $=13,8$ $22,9 \mu \mathrm{m} ;$ Lce $=16,8-29,1 \mu \mathrm{m} ;$ Lse $=7,6-14,5 \mu \mathrm{m}$; I $=4,6-8,2 \mu \mathrm{m}$.

Material estudado: BRASIL. MARANHÃO: Barreirinhas, Lagoa do Caçó, 12-IV-1999, M.J.Dellamano-Oliveira s.n. (SP336288); idem, 13-IV-1999, M.J.DellamanoOliveira s.n. (SP336289); idem, 14-IV-1999, M.J. Dellamano-Oliveira s.n. (SP336291); idem, 15-IV1999, M.J. Dellamano-Oliveira s.n. (SP336292); 


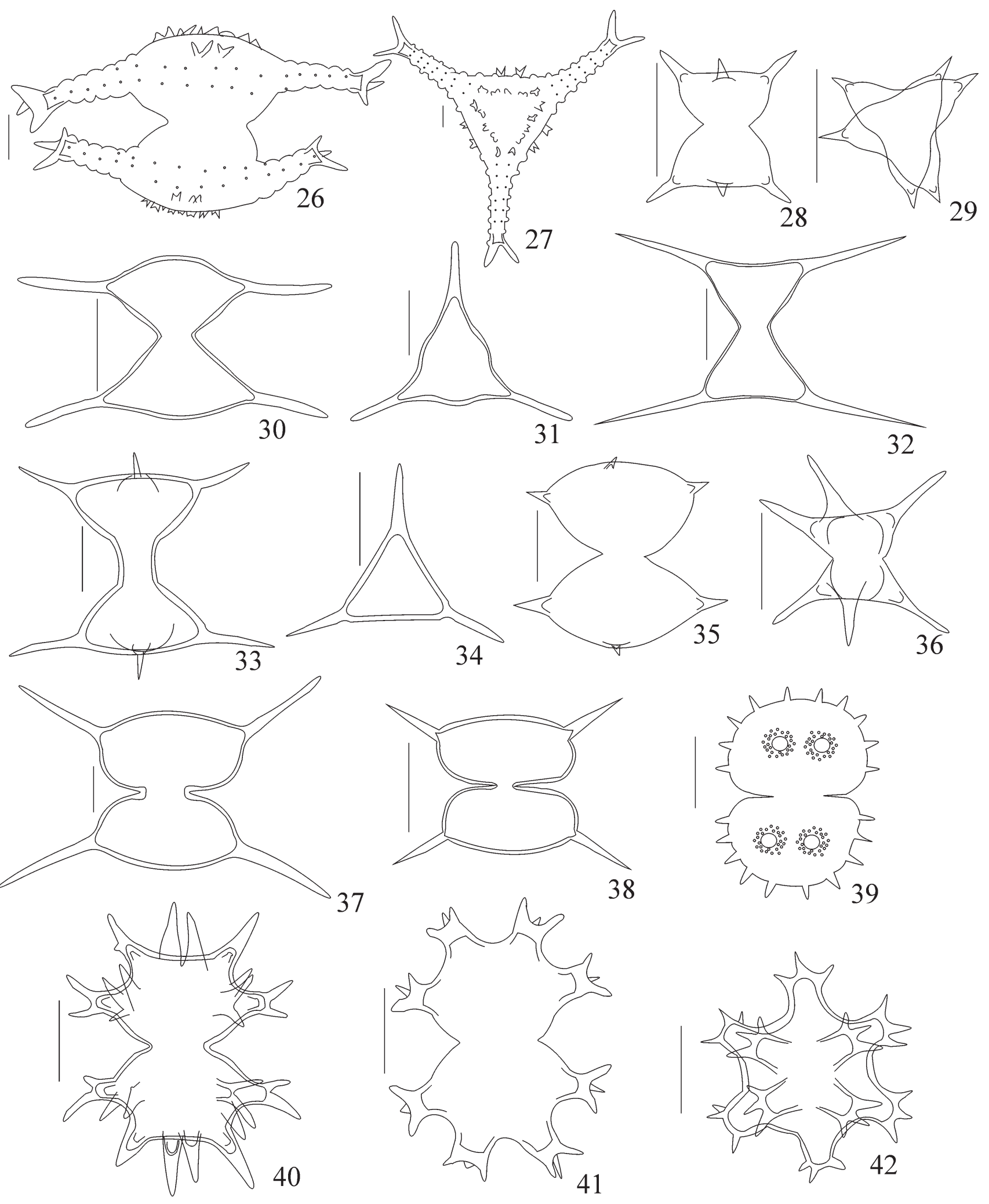

Figuras 26-42. Espécies de Staurastrum, Staurodesmus e Xanthidium da lagoa do Caçó. 26. Staurastrum vestitum var. subanatinum. 27. Staurastrum vestitum var. subanatinum, vista apical. 28. Staurodesmus connatus var. connatus. 29. Staurodesmus connatus var. connatus, vista apical. 30. S. dejectus var. borealis f. amazonensis, 31. S. dejectus var. borealis f. amazonensis, vista apical. 32. S. indentatus. 33. S. mammilatus. 34. S. mammilatus, vista apical. 35. S. megacanthus var. minus. 36. S. tortus. 37. S. validus var. validus. 38. S. validus var. subvalidus . 39: Xanthidium cf. eckertii. 40. X. cf. fragile. 41. Xanthidium regulare. 42. Xanthidium regulare, vista apical. Barras de escala $=10 \mu \mathrm{m}$. 

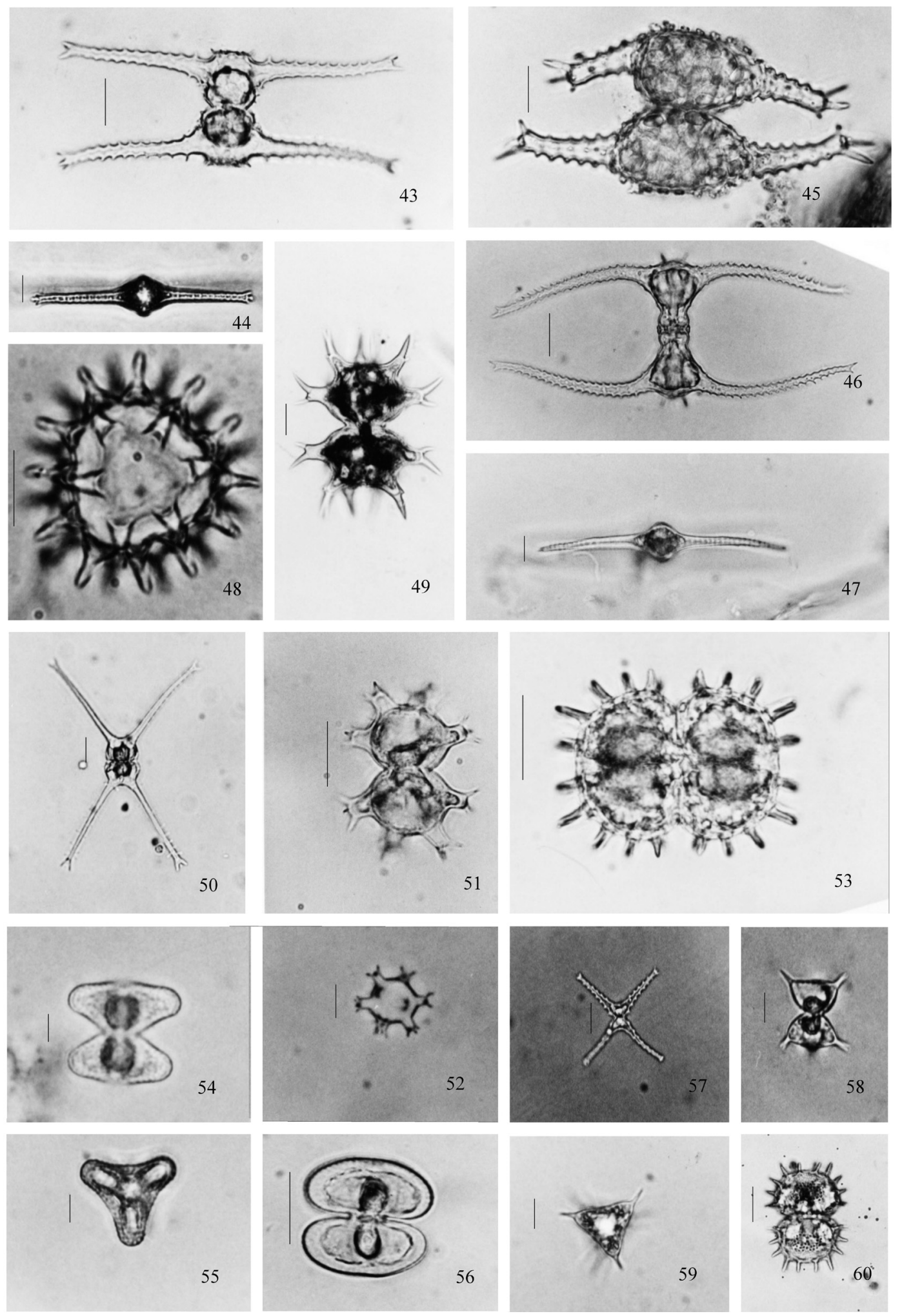

Figuras 43-60. Espécies de Staurastrum e Xanthidium da lagoa do Caçó. 43. S. triundulatum var. floridense. 44. S. triundulatum var. floridense, vista apical. 45. S. vestitum var. subanatinum. 46. S. leptocladum var. cornutum. 47. S. leptocladum var. cornutum, vista apical. 48. S. teliferum var. grönbladii. 49. Xanthidium fragile. 50. Staurastrum columbetoides var. ginsbergerii. 51. Xanthidium regulare. 52. Xanthidium regulare, vista apical. 53, 60. X. eckertii. 54. S. dilatatum f. dilatatum. 55. S. dilatatum f. dilatatum, vista apical. 56. Staurastrum muticum f. minus. 57. S. tetracerum. 58. S. connatus var. connatus. 59. S. connatus var. connatus, vista apical. Barras de escala da figura $49=20 \mu \mathrm{m}$, demais figuras $=10 \mu \mathrm{m}$. 
idem, 16-IV-1999, M.J. Dellamano-Oliveira s.n. (SP336294); idem, 17-IV-1999, M.J. DellamanoOliveira s.n. (SP336296); idem, 19-IV-1999, M.J. Dellamano-Oliveira s.n. (SP336290).

Primeiro registro de ocorrência dessa espécie no estado do Maranhão. Os espécimes examinados assemelham-se quanto a forma das semicélulas e a vista apical à $X$. regulare Nordst., porém, não puderam ser identificados com nenhuma variedade já descrita.

O estudo qualitativo da comunidade fitoplanctônica da lagoa do Caçó, realizado por Dellamano-Oliveira et al. (2003) revelou que a classe Zygnemaphyceae foi a mais representativa (107 espécies, 38 variedades e cinco formas), composta quase que exclusivamente pela família Desmidiaceae que contribuiu com 98\% do total de táxons identificados. A elevada diversidade da família Desmidiaceae é atribuída às características limnológicas da lagoa do Caçó, tais como: $\mathrm{pH}$ levemente ácido (menor que 7,0), baixa condutividade elétrica, temperatura da água em torno de $29^{\circ} \mathrm{C}$ e baixa concentração de nutrientes.

A maioria dos táxons identificados no presente estudo foi registrada no período chuvoso, tanto na zona limnética, quanto na litorânea. A precipitação durante este período, associada à presença mais intensiva de macrófitas aquáticas que possibilitam grande variedade de habitats, contribuíram para a maior abundância de táxons neste período.

Dos 29 táxons infra-específicos identificados na lagoa do Caçó, 26 são pioneiros para o Estado do Maranhão, excetuando-se apenas Staurastrum rotula, S. teliferum var. gröenbladii e Staurodesmus validus var. subvalidus.

\section{Agradecimentos}

À equipe do Projeto de Pesquisa "Utilização de marcadores limnológicos e sedimentológicos na bacia da lagoa do Caçó (Norte do Maranhão)" e à Fundação de Amparo à Pesquisa do Estado de São Paulo (FAPESP), pela viabilização das coletas; ao Programa de Pós-graduação em Ecologia e Recursos Naturais (PPG-ERN) da Universidade Federal de São Carlos (UFSCar), pelo apoio logístico; ao Conselho Nacional de Pesquisa Científica e Tecnológica (CNPq), pela concessão de bolsa de pós-graduação ao primeiro e terceiro autores (processos 130687/1999-5 e 146515/99-4, respectivamente).

\section{Literatura citada}

Almeida, I.C.S., Ferreira-Correia, M.M., Dourado, E.C.S. \& Caridade, E.O. 2005. Comunidade fitoplanctônica do lago Cajari, Baixada Maranhense, no período de cheia. Boletim do Laboratório de Hidrobiologia 18: 1-9.

Araújo, A. 2000. A comunidade fitoplanctônica de um sistema lacustre em curto período de tempo (estações seca e chuvosa) - no Parque Nacional dos Lençóis Maranhenses, Maranhão. Dissertação de Mestrado, Universidade de São Paulo, São Carlos.

Araújo, A., Pessoa, C.D., Correia, M. \& Ibañez, M.S.R. 1998. Fitoplâncton do rio Itapecuru, Maranhão, Brasil: uma contribuição ao conhecimento. Boletim do Laboratório de Hidrobiologia 11: 25-35.

Barbieri, R., Ibanez, M.S.R., Aranha, F.J., Correia, M.M.F., Reid, J.W. \& Turner, P. 1989. Plâncton, produção primária e alguns fatores físico-químicos de dois lagos da baixada Maranhense. Revista Brasileira de Biologia 49: 399-408.

Bicudo,C.E.M.\& Azevedo,M.T.P. 1977. Desmidioflórula paulista 1: gênero Arthrodesmus Ehr. ex Ralfs emend Arch. Bibliotheca Phycologica 36: 1-105.

Bicudo, C.E.M. \& Bicudo, R.M.T. 1965 . Contribuição ao conhecimento das desmidiaceae do Parque do Estado, São Paulo, II. Rickia 2: 39-54.

Bicudo, C.E.M. \& Castro, A.A.J. 1994. Desmidioflórula paulista 4: gêneros Closterium, Spinoclosterium. Bibliotheca Phycologica 95: 1-191.

Bicudo, C.E.M. \& Gil, F.G.2003. Different morphological expressions or taxonomical entities of Micrasterias arcuata (Desmidiales, Zygnemaphyceae). Revista Brasileira de Biologia 58: 645-655.

Bicudo, C.E.M. \& Martins D.V. 1988. Desmidias (Zygnemaphyceae) de Itanagra, Estado da Bahia, Brasil. Revista Brasileira de Biologia 49: 309-324.

Bicudo, C.E.M. \& Sormus, L. 1982. Desmidioflórula Paulista 2: gênero Micrasterias C. Agardh ex Ralfs. Bibliotheca Phycologica 57: 1-230.

Bicudo, C.E.M. \& Samanez, I.M. 1984. Desmidioflórula Paulista 3: gêneros Bambusina, Desmidium, Groenbladia, Hyalotheca, Onychonema, Phymatodocis, Spondylosium e Teilingia. Bibliotheca Phycologica 68: 1-139.

Bicudo, C.E.M., Sormus, L. \& Schetty, S.P. 1998. Criptógamos do Parque Estadual das Fontes do Ipiranga, São Paulo, SP. Algas, 11: Zygnemaphyceae (Desmidiaceae, Haplotaenium, Pleurotaenium, Tetmemorus e Triploceras). Hoehnea 25: 33-43.

Brook, J.A. 1981. The biology of desmids. Blackwell Scientific Publications, Oxford.

Dellamano-Oliveira, M.J., Senna, P.A.C.\& Taniguchi, G.M. 2003. Limnological characteristics and seazonal changes in density and diversity of the phytoplanktonic 
community at the Caçó pond, Maranhão State, Brazil. Brazilian Archives of Biology and Technology 46: 641-651.

Eskinazi-Leça, E., Gusmão, L. M. O. \& Silva, M.G.G. 1985. Microfitoplâncton da Baia do Capim (Estado do Maranhão-Brasil). In: Anais da VIII Reunião Nordestina de Botânica, Recife. Resumos da VIII Reunião Nordestina de Botânica, Sociedade Botânica do Brasil, pp. 57-81.

Faustino, S.M.M. \& Bicudo, C.E.M. 2004. Genus Bourrellyodesmus (Desmidiaceae, Zygnemaphyceae) in the state of São Paulo, Brazil. Revista Brasileira de Botânica 27: 667-670.

Ferragut, C., Lopes, M.R.M., Bicudo, D.C., Bicudo, C.E.M. \& Vercellino, I.S. 2005. Ficoflórula perifítica e planctônica (exceto Bacillariophyceae) de um reservatório oligotrófico raso (Lago do IAG, São Paulo). Hoehnea 32: 137-184.

Förster,K.1964.Desmidiaceen aus Brasilian. 2. Teil: Bahia, Goyaz, Piauhy und Nord-Brasilien. Hydrobiologia 23: 321-505.

Förster, K. 1969. Amazonische Desmidieen, 1. Areal Santarém. Amazoniana 2: 5-116.

Förster, K. 1974. Amazonische Desmidieen. 2 Areal Maués-Abacaxis. Amazoniana 5: 135-242.

Gil,F.G. \& Bicudo,C.E.M. 2000. Ecology of Micrasterias arcuata var. arcuata and M. arcuata var. expansa (Desmidiaceae, Zygnemaphyceae) in the Açude Jacaré, Southern Brazil. Algological Studies 98: 71-89.

Huszar, V.L.M. 1994. Fitoplâncton de um lago amazônico impactado por rejeito de bauxita (lago Batata, Pará, Brasil): estrutura da comunidade, flutuações espaciais e temporais. Tese de Doutorado, Universidade Federal de São Carlos, São Carlos.

Huszar, V.L.M. \& Sophia, M.G. 1996. Planktonic desmids of three Amazonian systems (Lake Batata, Lake Mussará and Trombetas River), Pará, Brazil. Amazoniana 14: 75-90.

Lavôr-Fernandes, G. 1987. Contribuição ao estudo das diatomáceas (Bacillariophyceae) da lagoa da Jansen (São Luís - MA). Caderno Pesqueiro 3: 34-52.

Lavôr-Fernandes, G. 1988. Microfitoplâncton da baía de São Marcos (São Luís, Maranhão, Brasil). Gayana 45: 265-274.

Margalef, R. 1983. Limnologia. Omega, Barcelona.

Marinho,M.M.\& Sophia, M.G. 1997. Desmidioflórula do Açude de Jacaré, Município de Moji-Guaçu, SP, Brasil. Hoehnea 24: 37-53.

Martins, D.V. \& Bicudo, C.E.M. 1987. Desmídias da Ilha de Tinharé, Estado da Bahia, Brasil. Revista Brasileira de Biologia 47: 1-16.

Matsuzaki, M.M., Negrão, J.L. \& Rocha, A.A. 2004. Comunidade fitoplanctônica de um pesqueiro na cidade de São Paulo. Revista de Saúde Pública 38: 679-686.

Nimer,E. 1989. Climatologia do Brasil. Instituto Brasileiro de Geografia e Estatística, Rio de Janeiro.

Nogueira, N.M.C., Barbieri, R., Costa Neto, J.P. \& Rocha O. 2005. Composition and temporal changes of phytoplankton community in lake Quebra-Pote, MA, Brazil. Acta Limnologica Brasiliensia 17: 419-431.

Oliveira, D.B.F., Eskinazi-Leça, E. \& Köning, M.L. 1986. Microfitoplâncton da Baía de Mangunça (Estado do Maranhão - Brasil). Boletim Técnico EMPARN 15: $1-30$.

Pompêo, M.L.M., Moschini-Carlos, V., Costa Neto, J.P., Cavalcante, P. R.S., Ibanez, M.S.R., FerreraCorreia, M.M. \& Barbieri, R. 1998. Heterogeneidade espacial do fitoplâncton no reservatório de Boa Esperança (Maranhão-Piauí, Brasil). Acta Limnologica Brasiliensia 10: 101-113.

Prescott, G.W., Bicudo, C.E.M. \& Vinyard, W.C. 1982. A Synopsis of North American Desmids. Part II. Desmidiaceae: Placodermae, Section 4. University of Nebraska Press, Lincoln.

Round, F.E. 1971. The taxonomy of the Chlorophyta, 2. British Phycological Journal 6: 235-264.

Silva, L.H.S. 1999. Fitoplâncton de um reservatório eutrófico (lago Monte Alegre), Ribeirão Preto, São Paulo, Brasil. Revista Brasileira de Biologia 59: 281303.

Sophia, M.G. 1987. Contribuição ao conhecimento das desmídias de hábito filamentoso do Estado do Rio de Janeiro, Brasil. Rickia 14: 21-35.

Sophia, M.G. 1991. Desmídias de hábito solitário (exceto Micrasterias C. Agardh ex Ralfs) do município do Rio de Janeiro e arredores, Brasil. Revista Brasileira de Biologia 51: 85-107.

Sophia, M.G. 1999. Desmídias de ambientes fitotélmicos bromelícolas. Revista Brasileira de Biologia 59: 141150.

Sormus, L. 1991. Desmidiaceae (Zygnemaphyceae) da Serra do Cipó, Estado de Minas Gerais, Brasil, 1: Gênero Micrasterias C. Agardh ex Ralfs. Hoehnea 18: $1-29$.

Sormus, L. \& Bicudo, C.E.M. 1994. Criptógamos do Parque Estadual das Fontes do Ipiranga, São Paulo, SP. Algas, 6: Zygnemaphyceae (Closteriaceae). Hoehnea 21: 75-92.

Uherkóvich, G. 1976. Algen aus dem flüssen Rio Negro und Rio Tapajós. Amazoniana 5: 465-515.

Uherkóvich, G. 1981. Algen aus einigen Gewässern Amazonie. Amazoniana 7: 191-219.

Uherkóvich, G. 1984. Phytoplankton. In: H. Sioli (ed.). The Amazon: Limnology and landscape ecology of a mighty tropical river and is basin. Dr. W. Junk Publ., Dordrecht, pp. 295-310. 